\title{
Article
}

\section{Development of the Occupational Therapy Stroke Arm and Hand Record: An Upper Limb Treatment Schedule}

Jarvis, Kathryn, Reid, Gaynor, Edelstyn, Nicola and Hunter, Susan Available at http://clok.uclan.ac.uk/28250/

Jarvis, Kathryn ORCID: 0000-0001-5963-7346, Reid, Gaynor, Edelstyn, Nicola and Hunter, Susan (2014) Development of the Occupational Therapy Stroke Arm and Hand Record: An Upper Limb Treatment Schedule. British Journal of Occupational Therapy, 77 (3). pp. 126-133. ISSN 0308-0226

It is advisable to refer to the publisher's version if you intend to cite from the work. http://dx.doi.org/10.4276/030802214x13941036266469

For more information about UCLan's research in this area go to http://www.uclan.ac.uk/researchgroups/ and search for < name of research Group>.

For information about Research generally at UCLan please go to http://www.uclan.ac.uk/research/

All outputs in CLoK are protected by Intellectual Property Rights law, including Copyright law. Copyright, IPR and Moral Rights for the works on this site are retained by the individual authors and/or other copyright owners. Terms and conditions for use of this material are defined in the policies page.

\section{CLoK}

Central Lancashire online Knowledge www.clok.uclan.ac.uk

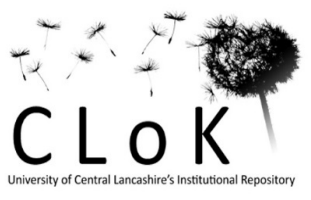


Development of the Occupational Therapy Stroke Arm and Hand Record (OTSTAR): an upper limb treatment schedule

\begin{abstract}
Introduction: This study aimed to develop a comprehensive occupational therapy treatment schedule of upper limb interventions for stroke survivors with reduced upper limb function.
\end{abstract}

Method: In a three-phased qualitative consensus study, twelve occupational therapists, from acute and community settings in North West England contributed to interviews and subsequently group discussions to design and pilot a treatment schedule. Interview data were analysed using thematic analysis; the themes were used to develop a framework for the schedule that was supported by and reflected the International Classification of Functioning framework. A draft schedule was the subject of a focus group and the resultant schedule was piloted in clinical practice by eight local occupational therapists working in neurological rehabilitation.

Results: Consensus was reached on three themes summarising aspects of function: interventions that address preparation for activity; functional skills (i.e. an aspect of function); function. Three additional themes summarised other aspects of therapy: advice and education; practice outside therapy sessions; psychosocial interventions. These themes became the main headings of the treatment schedule. The OT-STAR treatment schedule was piloted and found to be comprehensive and potentially beneficial to clinical practice.

Conclusion: The OT-STAR treatment schedule provides a tool for use in stroke research and clinical practice. 


\section{Introduction}

Strokes develop in 110,000 people in the UK each year (Department of Health 2005); it is estimated that between 55\% and 70\% (Nakayama et al 1994, Wade et al 1983) of stroke survivors admitted as an inpatient will experience upper limb (UL) dysfunction and require therapy to retrain functional activity. Therapists employ a number of complex interventions and techniques (Barreca et al 2003, Van Peppen et al 2004) in order to achieve this aim. Whilst a number of UL interventions studies have been undertaken with stroke participants, many of the interventions have not been clearly described, nor the effectiveness established, due to weak research design (Pomeroy and Tallis 2000). One of the key criticisms is that the current published research lacks clarity in describing the interventions under investigation and the comparison intervention (Pomeroy and Tallis 2000, Wolf et al 2006) resulting in studies that cannot be replicated or translated into practice. In order to explore the effectiveness of a complex intervention and to further evidence-based practice there needs to be a method of documenting accurately both the intervention under investigation and the control group intervention.

A therapy treatment schedule is a document that enables a therapist to record the details of the interventions undertaken in a given therapy session. There are five therapy treatment schedules documented in the stroke literature (Donaldson et al 2009, Hunter et al 2006, Pomeroy et al 2005, Rosewilliam et al 2009, Tyson and Selley 2004), although the terms protocol and recording tool have also been used to describe some of these documents. The details of the treatment schedules and the interventions included in each are recorded in table 1.

Insert table 1 about here 
Three of these schedules focus on the recovery of the upper limb (Donaldson et al 2009, Hunter et al 2006, Rosewilliam et al 2009). Two of these have been developed by physiotherapists (Donaldson et al 2009, Hunter et al 2006). Whilst there is evidence that occupational therapists and physiotherapists may use similar UL interventions (Barreca et al 2003, Intercollegiate Stroke Working Party 2008), it would be incorrect to assume that a physiotherapy treatment schedule reflects occupational therapy practice. Occupational therapy has developed from a strong history of using activity (occupation) to improve health (Wilcock 2001). The profession continues to reflect this, with therapists using activity both as a therapeutic tool and as an outcome. Occupational therapists enable people 'to engage as independently as possible in the activities (occupations) which enhance their health and wellbeing'(College of Occupational Therapists no date). Physiotherapy on the other hand has its roots in massage and exercise (Reynolds 1997). The Chartered Society of Physiotherapy (2013) states that physiotherapists work 'with people to identify and maximise their ability to move and function'. Whilst both professions share an interest in function, the manner in which the therapists practice their profession and the interventions they utilise reflects their different historical roots. For this reason, it is important that occupational therapy treatment schedules that reflect current occupational therapy practice are developed alongside the previously developed physiotherapy treatment schedules. Only one of the previously developed treatment schedules included occupational therapists in its development (Rosewilliam et al 2009), this schedule aimed to establish the most commonly used upper limb interventions, rather than a comprehensive treatment 
schedule that has the potential to record all upper limb occupational therapy interventions.

The aim of this study was to develop a comprehensive treatment schedule for documenting occupational therapy UL interventions following stroke, so that these interventions can be recorded more systematically in clinical practice and in future research.

\section{Methods}

The consensus development methodology used by Pomeroy et al (2005), Hunter et al (2006) and Donaldson et al (2009) underpinned this study. This was considered to be the most appropriate methodology as the aim was to develop a comprehensive treatment schedule to reflect practice, rather than rank the interventions in order of importance which would be the outcome of alternative consensus methodologies (Fink et al 1993, Gallagher et al 1993, Robson 2002). Consensus was sought on the interventions that comprise current clinical practice through three distinct phases, each with a clear objective:

Phase 1: semi-structured interviews to identify and describe the UL interventions used by individual occupational therapists when working with stroke survivors, to generate themes that would inform the development of a treatment schedule.

Phase 2: focus group discussion of the themes with occupational therapy participants to develop a draft treatment schedule. 
Phase 3: pilot of the draft treatment schedule to explore its usability in occupational therapy clinical practice.

All participants gave informed consent according to the Tenets of the Helsinki

Declaration; the study was approved by the National Research Ethics Service, North-West (Preston) Committee (10/H1016/58) and the local Research and Development (R\&D) units.

\section{Sample}

Occupational therapists were invited to participate if they met the following inclusion criteria to create an expert panel: Health Profession Council registered; working at Band 6 (occupational therapist with specialist skills) or above with a minimum of one year's experience working with service-users following stroke; currently working with service-users following stroke in an NHS Hospital Trust or a Primary Care Trust; selfreported familiarity with UL interventions following stroke. Previous studies (Donaldson et al 2009, Hunter et al 2006) indicated that between 6 and 12 therapists would be required to achieve data saturation. Further it is recognised that a sample size of between 6-12 is ideal for a focus group (Krueger and Casey 2000, Robson 2002). Ethical approval was sought and given for up to 12 participants, to ensure sufficient data were collected to achieve saturation (Parahoo 2006) and to ensure adequate participants for the focus group.

\section{Sampling and Recruitment}

Therapy Managers of three NHS Hospital Trusts and three Primary Care Trusts in the North West of England were asked to approach all occupational therapists who 
met the inclusion criteria. Purposive sampling (Silverman 2001) was used to ensure the sample included participants with a range of experience working with stroke survivors and post-qualification training in cognition and motor recovery. Each participant completed a questionnaire as part of the recruitment process to inform the sampling process.

Occupational therapists who participated in the Phase 1 interviews but were unable to participate in the Phase 2 group or the pilot, due to changes in job role, were replaced by a colleague who met the inclusion criteria and who subsequently underwent the same consent procedures as the participants recruited at the start of the study.

Participants were provided with details of the study both verbally and in writing. Written informed consent was obtained from all participants.

\section{Data collection and analysis}

All interviews and group meetings were audio-recorded, transcribed verbatim and kept in accordance with the Data Protection Act (1998) with identifiers removed. Field notes were made after each interview and group meeting. A log book and reflective notes were kept during the analysis of each phase, to record decisions and document the analysis pathway.

\section{Phase 1 - semi-structured interviews}

Following the development and pilot of the interview schedule, an individual semistructured interview of up to 90 minutes duration was undertaken with each 
participant. This allowed the collection of ideas from each participant, without influence from other participants. One researcher $(\mathrm{KJ})$ undertook all interviews. The first interview was reviewed for quality (Silverman 2000) by another member of the research team (GR), to identify potential sources of bias and note any changes required in interview technique.

Interviews were analysed by two members of the research team ( $\mathrm{KJ}$ and $\mathrm{SH}$ ) using constant comparison (Stanley 2006) and thematic content analysis with open coding (Boeije 2010) and a computer software package (NVivo 8). The aim of the analysis was to identify the following information:

- The UL interventions used by occupational therapists, with clear descriptions of the interventions

- Explanations of how and when specific UL interventions are used by occupational therapists

The two researchers independently extracted the data and undertook analyses using open-coding. Interventions were coded along with associated data, indicating definitions and details of the intervention, including how and when the intervention was used; themes were developed according to the reported aim of the intervention. Themes were compared and discrepancies discussed until agreement was reached. Using an iterative process, NVivo tree nodes were used to group the intervention codes and develop themes through axial coding (Boeije 2010) leading to maturing of themes. Areas of non-agreement were added to the group discussion schedule for Phase 2 and were subsequently discussed in the focus group.

\section{Phase 2 - focus group}


Prior to the focus group, participants were sent an overview of the emergent themes and were asked to individually consider their views on these and the associated definitions and descriptions of the interventions. The group meeting provided participants with the opportunity to report their views and consider the accuracy of the analysis in reflecting UL interventions in current occupational therapy practice in neurological rehabilitation. Participants discussed the proposed themes, definitions and structure and, through consensus agreement, validated the themes. The group was facilitated by two members of the research team (KJ and GR).

Analysis of the focus group data considered areas of participant consensus, areas of non-agreement and decisions agreed. Following this analysis, a draft treatment schedule was produced and distributed to each group participant for validation through member checking (Silverman 2001). It was also sent to participants who were unable to attend the group. Participants were invited to send comments or reflections to the research team. These were discussed by the research team and a judgement was made as to whether changes were required to the treatment schedule in line with the aim of producing a comprehensive document.

\section{Phase 3 - pilot of the draft treatment schedule}

Participants were asked to pilot the treatment schedule with five stroke-survivors with UL goals and to attend a second focus group, at which participants provided additional comments on the structure of the treatment schedule and the included interventions. They also provided feedback on the pilot of the treatment schedule in practice and considered how the schedule may be used in the future. Analysis of this 
second group meeting focused on issues of usability and feasibility of the treatment schedule following the pilot. Data were analysed as for Phase 2.

\section{Results}

\section{Phase 1 - semi-structured interviews}

Eight interviews were completed between $18^{\text {th }}$ October 2010 and $31^{\text {st }}$ January 2011. Participant clinical grade and number of years experience is summarised in table 2 . Five participants were employed by an NHS Hospital Trust and three by a Primary Care Trust. All eight participants had post-qualification training in motor control and three also reported post-qualification training in cognition.

Insert table 2 about here

Open coding resulted in 80 initial UL intervention codes. By the eighth interview, no additional interventions were being collected. Following discussion between the two researchers completing the analysis, it was agreed that data saturation had been reached and no further interviews were undertaken.

Using an iterative process, the UL intervention codes were considered and themed. The 'models' facility in NVivo 8 was used to organise the codes according to the therapist-reported purpose of each intervention. This led to the development of six broad themes:

- Interventions that addressed preparation for activity

- Interventions that addressed functional skills (i.e. an aspect of function)

- Interventions that address function 
- Advice and Education

- Practice outside formal therapy sessions

- Psychosocial interventions

The first three themes contained interventions that directly addressed preparation for function and functional activities, while the latter three themes summarised additional aspects of therapy. As the first three themes emerged, the researchers noted similarities between the initial descriptions of, and the interventions contained within, these themes and the International Classification of Functioning Disability and Health (ICF) constructs of Body Structure and Function, Activity and Participation (World Health Organization 2002). In an attempt to reduce bias, the developing themes were considered in light of other current and relevant theoretical frameworks: The Person-Environment-Occupation Model (Law et al 1996), the Model of Human Occupation (Keilhofner 2011), and the Occupational Therapy Practice Framework (American Occupational Therapy Association 2002). The researchers involved in the analysis agreed that the emerging themes were best described by the ICF. This decision recognised the substantial number of interventions that aimed to alter body structure and function in order to address preparation for activity, alongside a strong emphasis on the importance of activity and function to the participants' practice:

... we've... mentioned personal care and all various aspects of completing personal care or dressing, 'cos you need reach and grasp for all of these things. ...

... being able to use a wallet and not drop money, so I might practice that, err... putting items... taking items off shelves in shops... Lots of kitchen stuff. . Keyboard practice...... 
...Handwriting practice, I do a lot of activities to prep for handwriting. We do crafts activities.... I've done practicing dressing babies before with a young mum who needed to be able to look after the baby, so the scope is vast. They're probably some of the key things that we would do." Participant 10

The ICF framework was used to organise the interventions within the treatment schedule, and two documents were developed: one to record the themes and the interventions contained within that theme, and one containing definitions of the interventions. At the end of this phase, the six themes contained a total of $61 \mathrm{UL}$ interventions.

\section{Phase 2 - focus group}

Four participants, interviewed in Phase 1, attended the first focus group (table 2) on the $12^{\text {th }}$ May 2011. Two other participants who were unable to attend provided written comments.

Use of the ICF as a framework for guiding the treatment schedule was well received and approved by the group; no changes to the themes were suggested.

"I felt that it worked really, using the ICF framework and the headings, I thought that they were categorised well" Participant $\mathbf{3 0}$

"I agree, I read it really easily, it made sense to me." Participant 20

"I think a Band 5 with no experience could even follow it." Participant 12 
There was also evidence that the use of the ICF reflected current practice.

"...is everybody here using like the ICF as a kind of outcome measure......we have done on the ward for quite a while, and we are doing in the community team starting soon. So from my point of view, if we're starting to use the ICF as a kind of a measure and kind of marker, then this is really useful." Participant 30

The focus group also supported the analysis of the themes and the definitions.

"I think it's what makes us...what makes neuro OTs quite different from a lot of OTs. And I have always found it quite difficult to explain...what we do to achieve function. And I read this and I thought wow, you know, it really, really easily describes exactly what we do...this is what we do to achieve function, isn't it?" Participant 11

Minor amendments agreed at this group were integrated into the draft treatment schedule. 


\section{Phase 3 - pilot of the draft treatment schedule}

A total of eight occupational therapists (see table 2 for sample characteristics) piloted the treatment schedule over 28 treatment sessions and took part in the second focus group. Four of the participants had been involved in Phase 1.

The group gave a positive review and indicated that the treatment record was quick to complete, methodical, provided a good baseline and was helpful in goal setting. The guidance booklet was perceived as comprehensive and a good summary of all occupational therapy UL interventions. The group reported the treatment record as a potentially useful clinical tool alongside current notes.

Seven minor issues related to the usability of the treatment schedule were raised during this group meeting. As a result five minor amendments were agreed during the group meeting and appropriate changes were made subsequently to the documents. Four minor alterations were made to the structure of the treatment schedule and a clarification of one definition was also made. The final treatment schedule is shown in Appendix I.

During this group meeting there was also discussion about the potential uses of the treatment schedule. Although the original aim was to develop a treatment schedule for use in research and clinical practice, there was recognition that it may also be useful in training of staff,

"having the job of planning our training programme...I probably would trial this...in training now, if you agree to that. 
...it would generate discussion and training about what activities you could do for each different thing. So I think it would enable me to cover more detail in my training, without making any changes whatsoever..." Participant 10

and treatment planning,

“...maybe it could be a plan for the next week that I'm gonna do this, this and this...

... if someone does have to pick it up next week... they've got a master plan..."

\section{Participant 10}

The importance of space for free text to ensure professional standards could be met was acknowledged by the group participants. This allowed the inclusion of additional details that could not be recorded in the tick box design form.

\section{Discussion}

The OT-STAR has clinical utility as there are no known comprehensive occupational therapy schedules for UL interventions following stroke. The occupational therapy and physiotherapy UL treatment schedules, although developed through a similar process, differ in design. Each reflects the professions core skills and approaches in this field. This demonstrates the importance of undertaking profession specific studies and not assuming that one profession can be described from the perspective of another, even if on the surface there appear to be similarities in their practice. Whilst occupational therapists and physiotherapists may both use a given intervention, the theoretical basis and their clinical reasoning in using the intervention may be very different, and a treatment schedule design should represent these 
differences. Occupational therapists are specialists in analysing activities or occupations and using these within therapy (Duncan 2002) as a means to improve outcomes in everyday occupations (Kristensen et al 2011). In the interviews and focus groups, the occupational therapists clearly reported that activities and occupations that were meaningful and important to stroke survivors were the main focus of their work. The links between the occupational therapy interventions and everyday activities or occupations were at times unclear, however utilising a framework to develop themes and understand the interventions in the context of occupations was a strength in this study. This approach clarified how interventions addressing body structure and function are a foundation to everyday occupations. Whilst the selection of the ICF in this study could be seen as a source of bias, measures were taken to ensure that the data substantiated the use of the ICF to organise the treatment schedule. Previous studies utilising the ICF in stroke rehabilitation (Drummond et al 2007, Metcalf et al 2007, Salter, Jutai, Teasell, Foley, and Bitensky 2005, Salter, Jutai, et al 2005a, 2005b), and the participants' narrative in the study also offer support for this approach.

It is recognised that whilst the ICF provides a framework for shared communication of functioning and health it does not aim to describe the whole of occupational therapy practice (Haglund and Henriksson 2003). Occupational therapists should continue to use profession specific tools and theoretical models to guide their practice (Haglund and Henriksson 2003). It is anticipated that this treatment schedule will be used within an occupational therapist's current practice, with the ICF terminology making implementation more intuitive (Royeen 2002).

The study demonstrates a path to 'better treatments' (Darzi 2008) using a flexible design that engages practitioners. The schedule has the potential to improve the 
reporting of UL interventions which may be utilised to further develop the clinical evidence base. The OT-STAR has the potential to further evidence-based practice through its use in clinical practice and research.

The study is limited by the lack of stroke survivor involvement in piloting the treatment schedule. Stroke survivors were consulted in the design of the protocol, but it would have been beneficial to collect stroke survivors' views on the treatment schedule during the pilot phase. In addition, choosing the ICF to guide the analysis may have been a source of bias. It was felt that the ICF described the UL interventions well; however, it is possible that an alternative theoretical framework may have provided an alternative interpretation.

\section{The Future}

Through a systematic review, Hunter et al (2006) identified two phases in the treatment schedule development process. The first phase encompasses development of a treatment schedule and a pilot of this in practice. The second phase tests the generalisability and reliability of the treatment schedule. This second phase needs to be undertaken for the OT-STAR. The current study has been undertaken in collaboration with occupational therapists in the North West of England; further work is required to test the generalisability of the treatment schedule to therapists work in other geographical areas of the United Kingdom. The OT-STAR was designed as a means to report all occupational therapy UL interventions undertaken in a given therapy session; however, it is possible that therapists may classify and therefore report the interventions in different ways. The intra-rater and 
inter-rater reliability of the treatment schedule should also be addressed in future studies.

\section{Conclusion}

The OT-STAR, a comprehensive treatment schedule for documenting occupational therapy UL interventions following stroke, has been developed using a consensus development methodology. It provides a tool that occupational therapists can use in their clinical practice to systematically record their interventions. In conjunction with two established physiotherapy treatment schedules for the UL, the OT-STAR also provides a means to comprehensively document UL therapy for future research.

\section{Acknowledgements}

We wish to thanks the participating occupational therapists for their important contribution to the content of the treatment schedule and the piloting of the schedule in clinical practice.

\section{Declaration of interest:}

Financial support was received from The Constance Owen Fund for transcription services and data analyses costs. The authors report no other declarations of interest. 
Insert appendix 1 about here 
Table 1: Summary of Previous Treatment Schedules

\begin{tabular}{|c|c|c|c|}
\hline Study & $\begin{array}{l}\text { No and profession } \\
\text { of therapy } \\
\text { participants }\end{array}$ & $\begin{array}{l}\text { Summary of } \\
\text { Consensus } \\
\text { Methods }\end{array}$ & $\begin{array}{l}\text { Content of Treatment } \\
\text { schedule }\end{array}$ \\
\hline $\begin{array}{l}\text { Donaldson, C, et al, } A \\
\text { treatment schedule of } \\
\text { conventional physical } \\
\text { therapy provided to } \\
\text { enhance upper limb } \\
\text { sensorimotor recovery } \\
\text { after stroke: Expert } \\
\text { criterion validity and } \\
\text { intra-rater reliability. } \\
\text { Physiotherapy, } 2009 \text {. } \\
\text { 95(2): p. } 110-119 .\end{array}$ & $\begin{array}{l}11 \text { Physiotherapists } \\
\text { (consensus } \\
\text { development } \\
\text { element of study) }\end{array}$ & $\begin{array}{l}\text {-Individual semi- } \\
\text { structured interviews } \\
\text {-Focus group } \\
\text {-Pilot }\end{array}$ & $\begin{array}{l}\text { Soft tissue mobilisation } \\
\text { Joint mobilisation } \\
\text { Facilitation of muscle } \\
\text { activity/movement } \\
\text { Positioning } \\
\text { Specific sensory input } \\
\text { Splinting techniques } \\
\text { Exercise to increase strength } \\
\text { Balance and mobility } \\
\text { incorporating upper limb } \\
\text { activity } \\
\text { Upper limb functional tasks } \\
\text { Education for patient and/or } \\
\text { carer } \\
\text { Other } \\
\text { interventions/techniques }\end{array}$ \\
\hline $\begin{array}{l}\text { Hunter, SM, et al., } \\
\text { Development of } \\
\text { treatment schedules for } \\
\text { research: a structured } \\
\text { review to identify } \\
\text { methodologies used } \\
\text { and a worked example } \\
\text { of 'mobilisation and } \\
\text { tactile stimulation' for } \\
\text { stroke patients. } \\
\text { Physiotherapy, } 2006 . \\
\text { 92(4): p. } 195-207 .\end{array}$ & 7 Physiotherapists & $\begin{array}{l}\text {-Individual semi- } \\
\text { structured interviews } \\
\text {-Focus group } \\
\text {-Pilot }\end{array}$ & $\begin{array}{l}\text { Passive movements } \\
\text { Accessory movements } \\
\text { Massage } \\
\text { Soft tissue stretch } \\
\text { Placing the hand } \\
\text { Isolated/selective joint } \\
\text { movement } \\
\text { Compression } \\
\text { Sensory input } \\
\text { Patterns of co-ordinated } \\
\text { movement }\end{array}$ \\
\hline $\begin{array}{l}\text { Pomeroy, VM, et al., } \\
\text { Development of a } \\
\text { schedule of current } \\
\text { physiotherapy treatment } \\
\text { used to improve } \\
\text { movement control and } \\
\text { functional use of the } \\
\text { lower limb after stroke: } \\
\text { a precursor to a clinical } \\
\text { trial. Neurorehabilitation } \\
\text { \& Neural Repair, } 2005 . \\
\text { 19(4): p. } 350-359 .\end{array}$ & 10 Physiotherapists & $\begin{array}{l}\text {-Individual semi- } \\
\text { structured interviews } \\
\text {-Focus group } \\
\text {-Pilot }\end{array}$ & $\begin{array}{l}\text { Soft tissue mobilisation } \\
\text { Facilitation of activity in } \\
\text { specific muscles } \\
\text { Facilitation of isolated } \\
\text { (selective) joint movement } \\
\text { Facilitation of of-ordinated } \\
\text { (combined) movement } \\
\text { Resistive exercise } \\
\text { Specific sensory input } \\
\text { Splinting techniques } \\
\text { Function (lying to sitting, } \\
\text { sitting to standing, standing } \\
\text { to walking and walking } \\
\text { onwards) }\end{array}$ \\
\hline $\begin{array}{l}\text { Rosewilliam, SB, et al., } \\
\text { An approach to } \\
\text { standardize, quantify } \\
\text { and record progress of } \\
\text { routine upper limb } \\
\text { therapy for stroke } \\
\text { subjects: the Action } \\
\text { Medical Research } \\
\text { Upper Limb Therapy } \\
\text { protocol. Hand Therapy, } \\
\text { 2009. 14(3): p. 60-68. }\end{array}$ & $\begin{array}{l}6 \text { Physiotherapists } \\
\text { and } 3 \text { Occupational } \\
\text { Therapists were } \\
\text { surveyed }\end{array}$ & $\begin{array}{l}\text { Systematic literature } \\
\text { search to develop } \\
\text { 'aims of therapy' } \\
\text { Survey } \\
\text { Nominal Group } \\
\text { discussion } \\
\text { Pilot of schedule }\end{array}$ & $\begin{array}{l}\text { Only therapeutic } \\
\text { interventions commonly used } \\
\text { by all therapists were } \\
\text { included. } \\
\text { The schedule is problem } \\
\text { orientated, with treatment } \\
\text { aims including: sensory } \\
\text { education, facilitation, early } \\
\text { sensory stimulation, cross } \\
\text { facilitation, bilateral activities, } \\
\text { desensitisation, elicit muscle } \\
\text { activity, strengthening, } \\
\text { maintain tissue length, }\end{array}$ \\
\hline
\end{tabular}




\begin{tabular}{|c|c|c|c|}
\hline & & & $\begin{array}{l}\text { decrease activity to passive } \\
\text { movement, relaxation, } \\
\text { isolation of movements, train } \\
\text { coordination, fine motor } \\
\text { control/dexterity } \\
\text { Stimulation of functional } \\
\text { movement } \\
\text { Patient-orientated goal }\end{array}$ \\
\hline $\begin{array}{l}\text { Tyson, S.F. and Selley, } \\
\text { A. The development of } \\
\text { the Stroke } \\
\text { Physiotherapy } \\
\text { Intervention Recording } \\
\text { Tool (SPIRIT). Disability } \\
\text { \& Rehabilitation, } 2004 \text {. } \\
\text { 26(20): p. 1184-1188. }\end{array}$ & $\begin{array}{l}\text { Number involved in } \\
\text { initial development of } \\
\text { treatment schedule } \\
\text { not stated (senior } \\
\text { clinicians from } 2 \\
\text { stroke units) } \\
\text { piloted by } 35 \\
\text { Physiotherapists }\end{array}$ & $\begin{array}{l}\text { Literature search } \\
\text { Discussion with } \\
\text { experienced } \\
\text { clinicians } \\
\text { Pilot of schedule } \\
\text { Consultation with } \\
\text { participating } \\
\text { clinicians post-pilot }\end{array}$ & $\begin{array}{l}\text { Preparation for treatment } \\
\text { Facilitated movements } \\
\text { Balance activities } \\
\text { Walking activities } \\
\text { Practising functional activities } \\
\text { Organising patient activities } \\
\text { for independent practice } \\
\text { Teaching health care } \\
\text { professionals or carers } \\
\text { Equipment provision or } \\
\text { training }\end{array}$ \\
\hline
\end{tabular}

Treatment schedule, therapy protocol and recording tool are all terms used within the literature to describe a record of the therapy interventions. 
Table 2: Participants' experience and Current Job Band for each Phase of the Study

\begin{tabular}{|c|c|c|c|c|}
\hline \multirow[b]{2}{*}{$\begin{array}{l}\text { Experience in Stroke } \\
\text { Rehabilitation (Years) }\end{array}$} & \multirow[t]{2}{*}{ Stage Involved } & \multicolumn{3}{|c|}{ Band } \\
\hline & & 6 & 7 & 8 \\
\hline \multirow{3}{*}{$1-2$} & Qnitervieng & 2 & & \\
\hline & Nominal Group & 1 & & \\
\hline & Pilot & 2 & 1 & \\
\hline \multirow{3}{*}{$3-5$} & Interview & 2 & & \\
\hline & Nominal Group & 2 & & \\
\hline & Pilot & 1 & 1 & \\
\hline \multirow{3}{*}{$6-10$} & anterview & & 2 & \\
\hline & Nominal Group & & & \\
\hline & Pilot & 1 & 1 & \\
\hline \multirow{3}{*}{$16-20$} & Interview & & 1 & \\
\hline & Nominal Group & & & \\
\hline & Pilot & & & \\
\hline \multirow{3}{*}{$20+$} & Interview & & & 1 \\
\hline & Nominal Group & & & 1 \\
\hline & Pilot & & & 1 \\
\hline
\end{tabular}




\section{References}

American Occupational Therapy Association (2002) Occupational therapy practice framework: domain and process. American Journal of Occupational Therapy, 56(6), 609-639.

Barreca S, Wolf SL, Fasoli S, Bohannon R (2003) Treatment interventions for the paretic upper limb of stroke survivors: a critical review. Neurorehabilitation \& Neural Repair, 17(4), 220-226.

Boeije H (2010) Analysis in qualitative research. London: Sage.

Chartered Society of Physiotherapy (2013) A Career in Physiotherapy Available at http://www.csp.org.uk/professional-union/careers-development/career-physiotherapy Accessed 23.05.13.

College of Occupational Therapists (no date) About Occupational Therapy Available at http://web1.cot.org.uk/homepage/about_occupational_therapy/Accessed 23 May, 2013.

Darzi AW (2008). Our NHS our future: NHS next stage review leading local change (Vol. 2012). London: Department of Health.

Department of Health (2005). Reducing brain damage: faster access to better stroke care. London: The Stationery Office.

Donaldson C, Tallis RC, Pomeroy VM (2009) A treatment schedule of conventional physical therapy provided to enhance upper limb sensorimotor recovery after stroke: Expert criterion validity and intra-rater reliability. Physiotherapy, 95(2), 110-119.

Drummond AS, Sampaio RF, Mancini MC, Kirkwood RN, Stamm TA (2007) Linking the Disabilities of Arm, Shoulder, and Hand to the International Classification of Functioning, Disability, and Health. Journal of Hand Therapy, 20(4), 336-344.

Duncan E (2002). Skills and processes in occupational therapy. In E. Duncan (Ed.), Foundations for practice in occupational therapy 4th ed., pp. 43-57. Philadelphia: Elsevier Ltd.

Fink A, Kosecoff J, Chassin M, Brook RH (1993) Concensus methods: characteristics and guidelines for use. American Journal of Public Health, 74(9), 979-983.

Gallagher M, Hares T, Spencer J, Bradshaw C, Webb I (1993) The nominal group technique: a research tool for general practice? Family Practice, 10(1), 76-81.

Haglund L, Henriksson C (2003) Concepts in occupational therapy in relation to the ICF. Occupational Therapy International, 10(4), 253-268.

Hunter SM, Crome P, Sim J, Donaldson C, Pomeroy VM (2006) Development of treatment schedules for research: a structured review to identify methodologies used and a worked example of 'mobilisation and tactile stimulation' for stroke patients. Physiotherapy, 92(4), 195-207.

Intercollegiate Stroke Working Party (2008) National clinical guidelines for stroke 3rd ed. London: Royal College of Physicians.

Keilhofner G (2011) Model of human occupation: theory and application 4th ed. Baltimore: Lippincott, Williams and Wilkins.

Kristensen HK, Persson D, Nygren C, Boll M, Matzen P (2011) Evaluation of evidence within occupational therapy in stroke rehabilitation. Scandinavian Journal of Occupational Therapy, 18(1), 11-25.

Krueger RA, Casey MA (2000) Focus groups: a prcatical guide for applied research. Thousand Oaks, California: Sage Publications Ltd.

Law M, Cooper B, Strong S, Stewart D, Rigby P, Letts L (1996) The Person-Environment-Occupation Model: a transactive approach to occupational performance. Canadian Journal of Occupational Therapy, 63(1), 9-23.

Metcalf C, Adams J, Burridge J, Yule V, Chappell P (2007) A review of clinical upper limb assessments within the framework of the WHO ICF...World Health Organization International Classification of Functioning, Disability and Health. Musculoskeletal Care, 5(3), 160-173.

Nakayama H, Jorgensen HS, Raaschou HO, Olsen TS (1994) Recovery of upper extremity function in stroke patients: the Copenhagen Stroke Study. Archives of Physical Medicine \& Rehabilitation, 75(4), 394-398. 
Parahoo K (2006) Nursing Research: Principles, Process and Issues 2nd ed. Basingstoke: Palgrave Macmillan.

Pomeroy VM, Cooke E, Hamilton S, Whittet A, Tallis RC (2005) Development of a schedule of current physiotherapy treatment used to improve movement control and functional use of the lower limb after stroke: a precursor to a clinical trial. Neurorehabilitation \& Neural Repair, 19(4), 350-359.

Pomeroy VM, Tallis RC (2000) Physical therapy to improve movement performance and functional ability poststroke. Part 2. A research direction. Reviews in Clinical Gerontology, 10(4), 381387.

Reynolds R (1997) Remembering our roots-let's not lose our footing. Physiotherapy Theory and Practice, 13, 177-178.

Robson C (2002) Real World Research. Oxford: Blackwell Publishing Ltd.

Rosewilliam SB, Bucher C, Roffe C, Pandyan AD (2009) An approach to standardize, quantify and record progress of routine upper limb therapy for stroke subjects: the Action Medical Research Upper Limb Therapy protocol. Hand Therapy, 14(3), 60-68.

Royeen CB (2002) Occupation reconsidered. Occupational Therapy International, 9(2), 111-120.

Salter K, Jutai JW, Teasell R, Foley NC, Bitensky J (2005) Issues for selection of outcome measures in stroke rehabilitation: ICF Body Functions. Disability \& Rehabilitation, 27(4), 191-207.

Salter K, Jutai JW, Teasell R, Foley NC, Bitensky J, Bayley M (2005a) Issues for selection of outcome measures in stroke rehabilitation: ICF activity. Disability \& Rehabilitation, 27(6), 315-340.

Salter K, Jutai JW, Teasell R, Foley NC, Bitensky J, Bayley M (2005b) Issues for selection of outcome measures in stroke rehabilitation: ICF participation. Disability \& Rehabilitation, 27(9), 507528.

Silverman D (2000) Doing Qualitative Research A Practical Handbook. London: Sage.

Silverman D (2001) Interpreting qualitative data: methods for analysing talk, text and interaction 2nd ed. London: Sage.

Stanley M (2006). A Grounded Theory of the Wellbeing of Older People In L. Finlay \& C. Ballinger (Eds.), Qualitative Research for Allied Health Professionals pp. 63-78. Chichester: Whurr Publishers Ltd.

Tyson SF, Selley A (2004) The development of the Stroke Physiotherapy Intervention Recording Tool (SPIRIT). Disability \& Rehabilitation, 26(20), 1184-1188.

Van Peppen RPS, Kwakkel G, Wood-Dauphinee S, Hendriks HJM, Van der Wees PJ, Dekker J (2004) The impact of physical therapy on functional outcomes after stroke: what's the evidence? Clinical Rehabilitation, 18(8), 833-862.

Wade DT, Langton-Hewer R, Wood VA, Skilbeck CE, Ismail HM (1983) The hemiplegic arm after stroke: measurement and recovery. Journal of Neurology, Neurosurgery \& Psychiatry, 46(6), 521-524.

Wilcock A (2001). A History of Occupational Therapy Occupation for Health: A Journey from Self Health to Prescription Vol. 1, pp. 1-19. London: British Association of Occupational Therapists.

Wolf SL, Winstein CJ, Miller JP, Taub E, Uswatte G, Morris D, Giuliani C, Light KE, Nichols-Larsen D, Investigators $\mathrm{E}$ (2006) Effect of constraint-induced movement therapy on upper extremity function 3 to 9 months after stroke: the EXCITE randomized clinical trial. J.A.M.A., 296(17), 2095-2104.

World Health Organization. (2002). Towards a common language for functioning, disability and health ICF 